\section{ekf}

WYSOKÁ ŚKOLA BÁŇSKÁ OSTRAVA EKONOMICKÁ FAKULTA

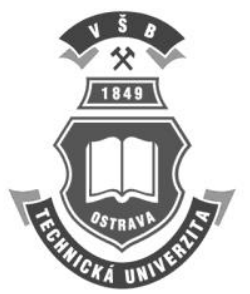

\title{
Monitoring sustainable development and decoupling in the EU
}

\author{
Magdaléna DRASTICHOVÁa \\ ${ }^{a}$ Department of Regional and Environmental Economics, Faculty of Economics, VŠB-Technical University of Ostrava, \\ Sokolská 33, 70121 Ostrava, Czech Republic.
}

\begin{abstract}
The EU formulated a long-term sustainable development strategy in 2001 and renewed it in 2006. The progress of the EU against the challenges laid out in this strategy has been monitored by EU Sustainable Development Indicators. The aim of this paper is to examine how the EU has approached the sustainable development path using selected Sustainable Development Indicators. In this paper, attention is especially paid to resource productivity, material consumption and greenhouse gas emissions in the EU economies and particularly in their transport sectors. The development of these indicators has varied across the EU countries. The reduction of greenhouse gas emissions in the overall economies has shown favourable trends, in contrast to their development in the transport sectors. Stable or decreasing domestic material consumption (DMC) in the EU has often been associated with relatively low GDP growth rates and conversely high GDP growth rates with moderate or high increases in DMC. Therefore, the significant changes in trends due to the economic crisis are not the result of structural changes but rather a temporary interruption of longer-term trends. The EU has still not begun to fully follow the sustainable development path.
\end{abstract}

\section{Keywords}

Decoupling, material and energy consumption, resource productivity, sustainable development, sustainable development indicators.

JEL Classification: Q54, Q56

\footnotetext{
*magdalena.drastichova@vsb.cz
} 


\title{
Monitoring sustainable development and decoupling in the EU
}

\author{
Magdaléna DRASTICHOVÁ
}

\section{Introduction}

Sustainable development (SD) is a global challenge that requires a progressive transformation of economies (Hediger, 2004), specifically substantial changes in production processes and lifestyles (FEEM, 2011). According to the WCED (1987), SD is development that meets the needs of the present without compromising the ability of future generations to meet their own needs. However, this term is still vague. Despite this fact, there is an emerging political consensus on the desirability of sustainable development (Daly, 1996). Since the 1992 United Nations (UN) Conference on Environment and Development in Rio de Janeiro, the EU has played a leading role in supporting the idea of balanced and sustainable development. SD would be of little interest if the current patterns of economic development were judged to be sustainable. However, this is not the case (OECD, 2001).

To monitor the progress towards SD, a set of Sustainable Development Indicators (SDIs) has been developed in the EU. Selected SDIs are used in the analysis of this paper. The aim of this paper is to examine how the EU has approached the sustainable development path using selected Sustainable Development Indicators. The paper is divided into five sections. Following the introduction, the second section is the theoretical one and it focuses on the characteristics of the EU Sustainable Development Strategy (SDS). In this section, decoupling and the EU SDIs are also defined. The third section concentrates on the methodology. The SDIs that are used in the analytical part are described in more detail in this section. The fourth section is the analytical one and it is devoted to the evaluation of the development of the selected SDIs and the examination of the EU's sustainable development path. The last section summarizes the results of the analysis.

In the paper, the new member states are understood as the countries that have joined the EU since 2004 (12 countries except Croatia), ${ }^{1}$ whereas the older member states are the remaining EU-15 countries.

\footnotetext{
1 The most recent member state, Croatia, is not included in the analysis because of its short membership of the EU.
}

\section{Sustainable Development in the EU}

Sustainable development is a fundamental goal of the EU, enshrined in the Treaty. The strategy for sustainable development (SD) was adopted in 2001 and it provides an EU-wide policy framework to deliver sustainable development.

\subsection{Characteristics of the EU Sustainable Devel- opment Strategy (SDS)}

Sustainable development became a fundamental objective of the EU in 1997 when it was included in the Treaty of Amsterdam as an overarching objective of EU policies (European Commission, 2014). ${ }^{2}$

The EU adopted a long-term strategy to dovetail the policies for economically, socially and environmentally sustainable development in 2001 (European Council, 1999). This strategy provides an EU-wide policy framework to deliver sustainable development, that is, to meet the needs of the present without compromising the ability of future generations to meet their own needs. Thus, its goal is to achieve sustainable improvement of the well-being of current and future generations. This strategy rests on four separate pillars - economic, social, environmental and global governance - that need to reinforce one another (Europa, 2009). That requires economic, social and environmental policies to be dealt with in a mutually reinforcing way (European Council, 2001). The fundamental act, the Commission Communication of 15 May 2001 - A Sustainable Europe for a Better World: A European Union Strategy for Sustainable Development [COM (2001) 264 final] (Commission of the European Communities, 2001) - limited itself to formulating proposals with respect to the internal aspects of sustainable development. The Gothenburg European Council in June 2001 adopted the EU SDS on the basis of the above-mentioned Commission Communication.

In endorsing the SDS, the Gothenburg European Council recognised that the external dimension needed

\footnotetext{
${ }^{2}$ It was enshrined in Article 2 of the Treaty on European Union as amended by the Treaty of Amsterdam.
} 
to be developed further. Consequently, it also called on the Commission to consider the EU's contribution to global sustainable development. A subsequent Commission Communication of 13 February 2002 Towards a Global Partnership for Sustainable Development [COM (2002) 82 final] (Commission of the European Communities, 2002) - responded to this request. Thus, the external dimension was added to the EU SDS at the European Council in Barcelona in March 2002, ahead of the UN World Summit (held in Johannesburg in the summer of 2002). The texts of both Communications together form the basis of the comprehensive EU Sustainable Development Strategy (Commission of the European Communities, 2005). The European Council of June 2006 adopted a comprehensive renewed Sustainable Development Strategy for an enlarged EU, which is built on the original strategy of 2001. It sets out a coherent strategy for how the EU will comply with its long-standing commitment to meet the challenges of sustainable development. This especially requires the gradually changing of our current unsustainable consumption and production patterns, a more integrated approach to policy making, tackling the most urgent environmental challenges, such as climate change, as well as continuous support for global sustainable development taking into account the needs of developing countries, etc. (European Commission, 2014).

\subsection{Decoupling}

The term decoupling refers to breaking the link between two variables, often referred to as the driving force (mainly economic growth expressed in terms of GDP) and the environmental pressures (such as the generation of waste, the emission of pollutants to air or water and the use of natural resources, such as materials, energy or land). In other words, decoupling refers to breaking the link between environmental bads and economic goods (OECD, 2002). It points out the relative growth rates of a direct pressure on the environment and of an economically relevant variable to which it is causally linked. The purpose of decoupling indicators is to illustrate the interdependence between two different spheres, in this case between economic and environmental ones. Thus, these indicators measure the decoupling of environmental pressure from economic growth over a given period (OECD, 2003). Decoupling occurs when the growth rate of the economic driving force, for example the GDP, exceeds the growth rate of the environmental pressure over a given period (OECD, 2002). Moreover, decoupling can be either absolute or relative. Absolute decoupling implies that the environmental variable is stable or decreasing while the economic variable is growing. Decoupling is relative when the environmental variable is growing, but at a lower rate than the economic variable (OECD, 2002). It is obvious from the definition of decoupling that this process is a necessary component of achieving sustainable development path. Therefore, decoupling is also applied in the monitoring of the SD in the EU using decoupling indicators.

\subsection{The EU Sustainable Development Indicators}

Measuring the progress towards the agreed goals is an integral part of the EU SDS (Eurostat, 2013b). The 2006 renewed EU SDS calls for the European Commission to monitor the progress of the EU against the challenges laid out in this strategy and specifically to draw up a comprehensive set of SDIs. In order to address these requirements, Eurostat has developed a set of SDIs, with the help of a group of national experts known as the Task Force on Sustainable Development Indicators. The first set of indicators was adopted by the Commission in 2005 and then it was updated in 2007 in order to adjust to the renewed EU SDS. However, the development of the set of SDIs is still ongoing (Adelle and Pallemaerts, 2009). Monitoring reports that include SDIs are published by Eurostat every two years (Eurostat, 2013b).

The SDIs are organized in a theme-oriented framework and presented in ten themes. This framework reflects the key challenges of the EU SDS. Of more than one hundred indicators, twelve have been identified as headline indicators (see Table 1). They give an overall picture of whether the EU has achieved progress towards SD in terms of the objectives and targets established by this strategy (Eurostat, 2014a). However, there are different levels of the SDIs, which respond to different user needs. Besides the headline indicators that monitor the overall objectives related to the key challenges of the SDS, there are operational indicators related to the operational objectives of the SDS and the lead indicators in their subthemes. The third group of indicators consists of the explanatory indicators, which are related to actions described in the SDS. In addition, there are contextual indicators that either do not monitor a particular SDS objective directly or are not policy responsive (e.g. the number of persons in households). The last two groups are the indicators under development and indicators to be developed. Thus, the set of SDIs is flexible. New indicators can be included in response to changes in the priorities of the strategy (Eurostat, 2013b).

Examining the SDIs more in detail, we can see that among the headlines indicators two are designed to monitor the extent of decoupling between economic growth and environmental pressures. These are resource productivity and energy consumption of transport relative to GDP. While the former monitors the amount of gross value added (measured as the GDP) that an economy generates by using one unit of 
material (measured as the domestic material consumption), the latter compares the growth of transport energy consumption with the growth of GDP.

Seven themes of the SD correspond to the priority areas of the 2001 and 2002 Commission Communications (see above), while Production and Consumption Patterns and Good Governance arise from the Plan of Implementation adopted at the World Summit on Sustainable Development in 2002. The last remaining theme on Economic Development emphasises the economic dimension of sustainable development in the framework and links it to the Lisbon Process. Five themes are also consistent with the international engagements taken in the framework of the Millennium Declaration (see Table 1).

The framework is determined by policy themes that partially overlap. The scope of the themes differs substantially as some themes address a very specific domain, for example Climate Change and Energy, while others include a wide variety of general socioeconomic and environmental issues, e.g. Production and Consumption Patterns. Moreover, some driving forces, such as energy, affect developments in several themes, but cannot be included more times in the set of indicators (Commission of the European Communities, 2005). The themes are further divided into subthemes and actions of the SDS. For a more complete picture of the development of a particular theme, it is important to examine all the indicators within the theme, not only the headline indicators (Eurostat, 2014a).

\section{Description of the Indicators used in the Analy- sis}

In this section, the indicators used in the analysis are introduced, specifically three themes of the EU SDS with their indicators, which are examined in the paper in order to find out how the EU has approached the sustainable development path. In addition, to monitoring decoupling, the economic variable needs to be used. As a representative of the development of economic activity, the gross domestic product (GDP) at market prices in millions of euros, chain-linked volumes, with the reference year 2005 (at 2005 exchange rates) was used. It is referred to as the GDP or the real $G D P$. Only in the composition of the indicator of energy consumption of transport relative to GDP was the year 2000 used as a reference year in the GDP calculation (see below). All the data and indicators, including the GDP, were extracted from Eurostat (2013a).

The first theme of which the indicators for monitoring SD were used is Sustainable Consumption and Production, within which the EU sets out the objective of promoting sustainable consumption and production patterns. This includes addressing social and economic development within the carrying capacity of ecosystems and decoupling economic growth from environmental degradation in order to approach SD. The headline indicator in this theme is resource productivity, which is defined as the ratio between the GDP (in units of euros, in chain-linked volumes to the reference year 2005 at 2005 exchange rates) and the domestic material consumption (DMC). The DMC is the explanatory indicator in this theme. This is also used in the analysis in order to examine decoupling better. The DMC measures the total amount of materials directly used by an economy. It is defined as the annual quantity of raw materials extracted from the domestic territory of the focal economy plus all the physical imports minus all the physical exports (Eurostat, 2014c).

The second theme of which the SDIs were used is Sustainable Transport, which is the key challenge of the EU SDS. While meeting the economic, social and environmental needs, the transport systems' negative impacts on the economy, society and the environment

Table 1 The Sustainable Development Indicators - themes and eleven headline indicators

\begin{tabular}{|l|l|l|l|}
\hline $\begin{array}{l}\text { Socio-economic } \\
\text { development }\end{array}$ & $\begin{array}{l}\text { Growth rate of real GDP per } \\
\text { capita }\end{array}$ & $\begin{array}{l}\text { Climate } \\
\text { change and } \\
\text { energy }\end{array}$ & $\begin{array}{l}\text { Greenhouse gas emissions; } \\
\text { Share of renewable energy in gross final energy } \\
\text { consumption; Primary energy consumption }\end{array}$ \\
\hline $\begin{array}{l}\text { Sustainable consump- } \\
\text { tion and production }\end{array}$ & Resource productivity & $\begin{array}{l}\text { Sustainable } \\
\text { transport }\end{array}$ & $\begin{array}{l}\text { Energy consumption of transport relative to } \\
\text { GDP }\end{array}$ \\
\hline Social inclusion & $\begin{array}{l}\text { People at risk of poverty or } \\
\text { social exclusion }\end{array}$ & $\begin{array}{l}\text { Natural re- } \\
\text { sources }\end{array}$ & $\begin{array}{l}\text { Common bird index; } \\
\text { Fish catches taken from stocks outside safe } \\
\text { biological limits }\end{array}$ \\
\hline Demographic changes & $\begin{array}{l}\text { Employment rate of older } \\
\text { workers }\end{array}$ & $\begin{array}{l}\text { Global part- } \\
\text { nership }\end{array}$ & $\begin{array}{l}\text { Official development assistance as share of gross } \\
\text { national income }\end{array}$ \\
\hline Public health & $\begin{array}{l}\text { Healthy life years and life } \\
\text { expectancy at birth, by sex }\end{array}$ & $\begin{array}{l}\text { Good govern- } \\
\text { ance }\end{array}$ & No headline indicator \\
\hline
\end{tabular}

Source: Eurostat (2013b; 2014a); Commission of the European Communities (2005)

Note: The headline indicator Fish catches taken from stocks outside safe biological limits: Status of fish stocks managed by the $E U$ in the North-East Atlantic (in the table the shortened title is used) has been removed due to discontinuation of data collection. 
should be minimised. The headline indicator of this theme was also used in the analysis presented in this paper. This is the energy consumption of transport relative to GDP, which is defined as the ratio between the energy consumption of transport and the GDP (chain-linked volumes, at 2000 exchange rates). The energy consumed by all types of transport (road, rail, inland navigation and aviation) is covered, including commercial, individual and public transport, with the exception of maritime and pipeline transport (Eurostat, 2014d). In addition, the greenhouse gas emissions (GHG) from transport were analysed, which is the operation indicator in this theme as well as in the Climate Change and Energy theme (see below).

The overall objective of the Climate Change and Energy theme is to limit climate change and its costs and its negative effects on society and the environment (Eurostat, 2014b). The headline indicator, which was analysed in this study, is greenhouse gas emissions. This indicator monitors the trends in anthropogenic (man-made) emissions of six GHGs (the Kyoto basket of GHGs), ${ }^{3}$ weighted by their global warming potentials. The indicator does not include emissions and removals related to land use, land-use change and forestry (LULUCF), nor does it include emissions from international aviation and international maritime transport.

In order to complete the decoupling analysis, a simple cross-country regression analysis and the least squares method are used to examine the decoupling. Therefore, the relationship between the domestic material consumption in economies and the energy consumption of transport on the one hand and economic growth on the other hand in the EU countries was examined using this method as a supplement to the analysis of the development of decoupling indicators.

\section{Evaluation of Development in Selected Sustain- able Development Indicators in the $\mathrm{EU}$}

As indicated in the third section, two headline indicators of sustainable development were chosen to analyse decoupling in order to detect the sustainable development path in the EU. These are resource productivity in the Sustainable Consumption and Production theme and energy consumption of transport relative to GDP in the Sustainable Transport theme. In addition, two explanatory indicators in these themes were examined further, one of each theme, which were used in

\footnotetext{
3 These include the emissions of six GHGs of the Kyoto Protocol linked to the United Nations Framework Convention on Climate Change.
}

the calculation of the headline indicators and helped to explain in more detail some of the trends in these themes (areas). These indicators are the domestic material consumption in the first theme and the energy consumption in transport in the second one. As the last additional indicators, the greenhouse gas emissions in the overall economies and particularly the greenhouse gas emissions from transport were chosen because of their importance in tackling the climate change in order to achieve a sustainable development path. The first one is the headline and the second one the operational indicator in the Climate Change and Energy theme. The second one is the operational indicator in the Sustainable Transport theme as well.

\subsection{Development of Resource Productivity and Material Consumption}

Regarding the evaluation of changes in the Sustainable Consumption and Production theme, these changes show a rather mixed picture since 2000 . The development of the headline indicator is depicted in Figure 1. If the GDP grows more than the DMC, then the resource productivity grows as well. In the whole EU, we can detect increases in resource productivity in the period 2000-2009. This increase was particularly strong during the economic slowdown from 2000 to 2003, when the DMC experienced a downward trend. The DMC decreased annually in 2002 and 2003 with simultaneous slow growth in the real GDP, which led to absolute decoupling in the time of the economic slowdown. This development was reversed in 2004, when the DMC grew faster than the GDP $(4.918 \%$ and $2.532 \%$, respectively). It was followed by a period of relative decoupling from 2005 to 2007, during which the GDP grew at a slightly higher rate.

The annual rates of GDP growth were 2.079, 3.337 and $3.239 \%$ in 2005, 2006 and 2007, respectively (on average $2.885 \%$ ), whereas the growth rates of the DMC in these years were 1.191, 2.423 and $2.36 \%$, respectively (on average $1.991 \%$ ). A significant increase in the EU's resource productivity occurred in $2009(8.276 \%)$. This increase and the increase in 2008 are associated with the impacts of the global economic crisis and the following recession. In 2008, the DMC decreased and the GDP increased only slightly ($1.509 \%$ for the DMC and $0.341 \%$ for the GDP). In 2009 , the DMC decreased more than the GDP ($11.86 \%$ for the DMC and $-4.294 \%$ for the GDP).

Regarding the development in individual EU member states, only four countries achieved a decrease in their resource productivity in 2000-2009. These countries are Cyprus, Romania, Estonia and Portugal. In absolute figures (EUR per $\mathrm{kg}$ ), the decrease was most significant in Cyprus. However, the 


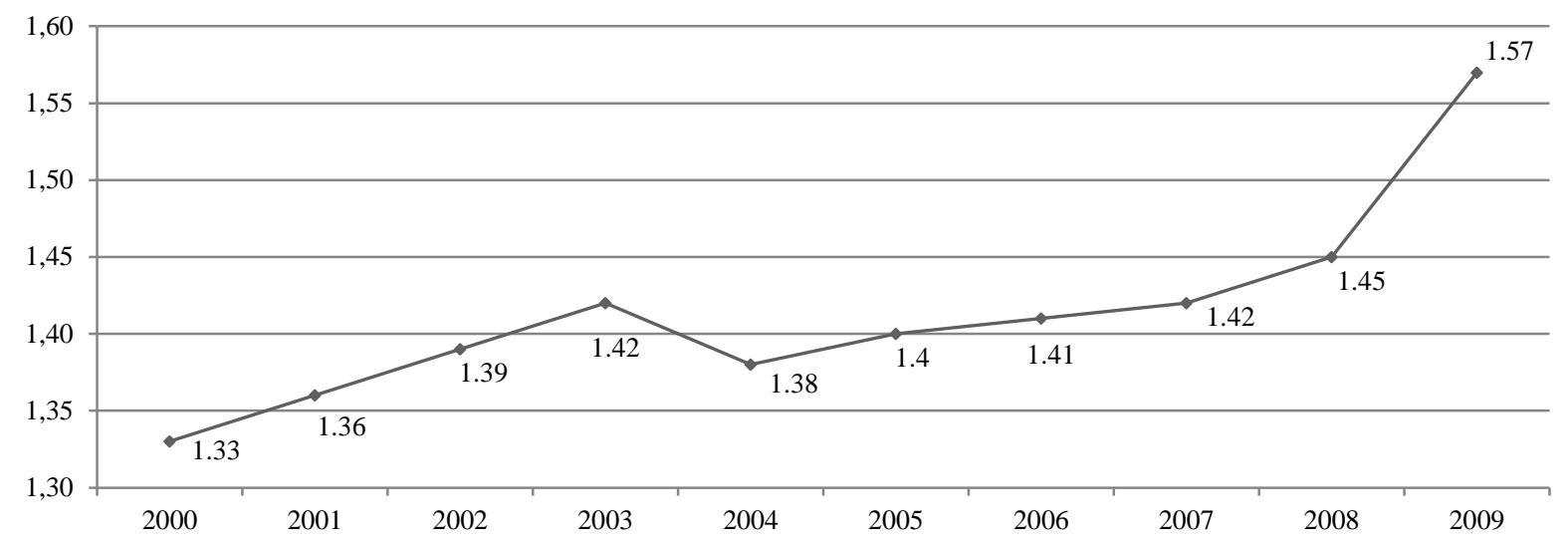

Figure 1 Resource productivity in the EU-27, EUR per kg Source: Eurostat (2013a), own elaboration

highest percentage decrease was apparent in Romania. As stated above, the year 2009 was significantly affected by the economic crisis, which was associated with a greater decrease in the DMC in comparison with the decrease in the real GDP. This resulted in an increase in productivity in most of the EU countries. On the other hand, from 2000 to 2007, the productivity dropped in Spain, Denmark, Lithuania and Slovenia besides the above-mentioned countries. This means that more EU countries experienced losses in resource productivity during the period, which does not include the years of economic crisis.

The largest increases in productivity in the period 2000-2009 were achieved by the Netherlands, Luxembourg, the United Kingdom (UK), Ireland and Italy (0.5 EUR per $\mathrm{kg}$ and more). At the same time, the highest percentage increase was shown by the economies of Ireland and Latvia. In the period 2000-2007, the greatest increase in productivity can be seen in Malta (0.68 EUR per kg). However, in 2009, the resource productivity significantly decreased annually in this country (see Figure 2). It is important to point out the fact that Malta was the only economy in which the DMC increased in 2009, by as much as $62.319 \%$. Other EU economies showed a decrease in the DMC, the most significant of which in percentage terms were observed in Lithuania, Latvia, Romania, Bulgaria and Spain (more than -20\%). Thus, most of the economies showed an increase in resource productivity in 2009 except small decreases in Germany (-0.01 EUR per $\mathrm{kg},-0.541 \%)$ and Estonia (-0.03 EUR per $\mathrm{kg}$, $7.895 \%)$ and a large decrease in Malta ( -2.23 EUR per $\mathrm{kg},-39.893 \%$ ). Therefore, this extraordinary development in Malta in 2009 in comparison with most of the EU economies resulted from the increase in the DMC and the simultaneous decrease in the GDP. This development was, among others, affected by the structure of the economy, which is almost exclusively oriented towards tourist traffic.
On average and in every year of the monitored period 2000-2009, four economies achieved the highest resource productivity among the EU countries. These economies are Malta, the Netherlands, Luxembourg and the UK. The development of resource productivity in these countries is depicted in the upper part of Figure 2. On the contrary, the lower levels of resource productivity, namely those lower than 1 EUR per $\mathrm{kg}$, were typical of the new member states (besides Malta), Portugal, Ireland and Finland, in every year of the monitored period, with the exception of Ireland in 2008 and 2009, which was again related to the economic crisis. This economy was hard hit by the crisis, which resulted in significant decreases in the DMC and increases in resource productivity in 2008 and 2009 following the previous annual increases in the DMC and decreases in productivity. Hence, in this country, the slight relative decoupling of the 20002007 period also turned into absolute decoupling in the period 2000-2009 (see also Figure 3). Overall, the lowest average levels of resource productivity in 2000-2009 were achieved by the economies of Bulgaria, Romania, Latvia and Estonia, which were followed by the other seven new member states, Portugal, Finland and Ireland.

It is necessary and appropriate to complete the assessment of trends in the headline indicator in the Sustainable Consumption and Production theme with the development of one of the associated explanatory indicators. This is the domestic material consumption (DMC), which has already been analysed because it is a component indicator in the calculation of the headline indicator, i.e. resource productivity. Comparing the growth rate of this indicator with the growth rate of the GDP, it can also be detected whether decoupling is taking place (see Figure 3 ).

Comparing the member states' average annual DMC with the real GDP growth rates in the period 2000-2009, absolute decoupling of resource use from 


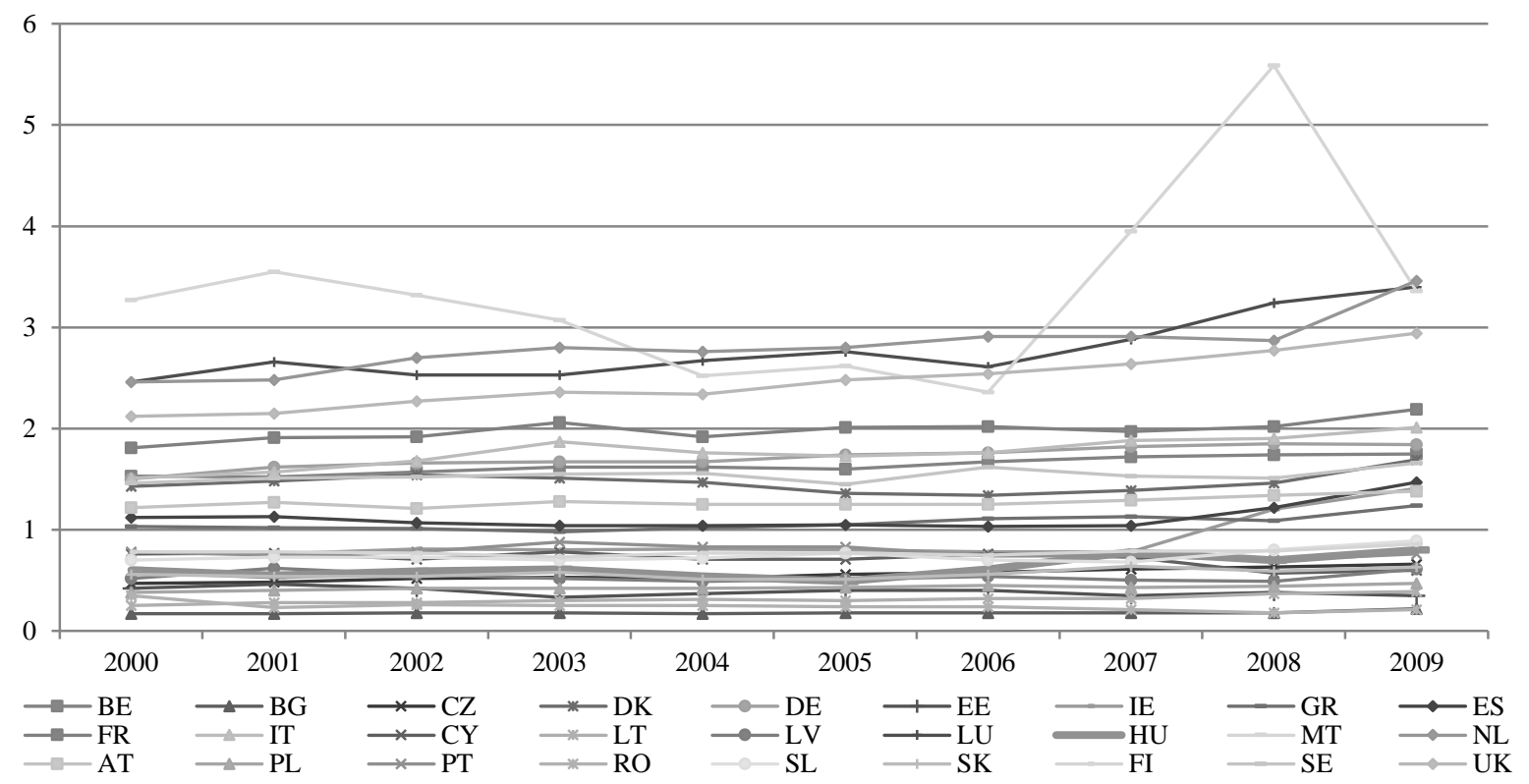

Figure 2 Resource productivity in the EU-27 countries, EUR per kg Source: Eurostat (2013a), own elaboration

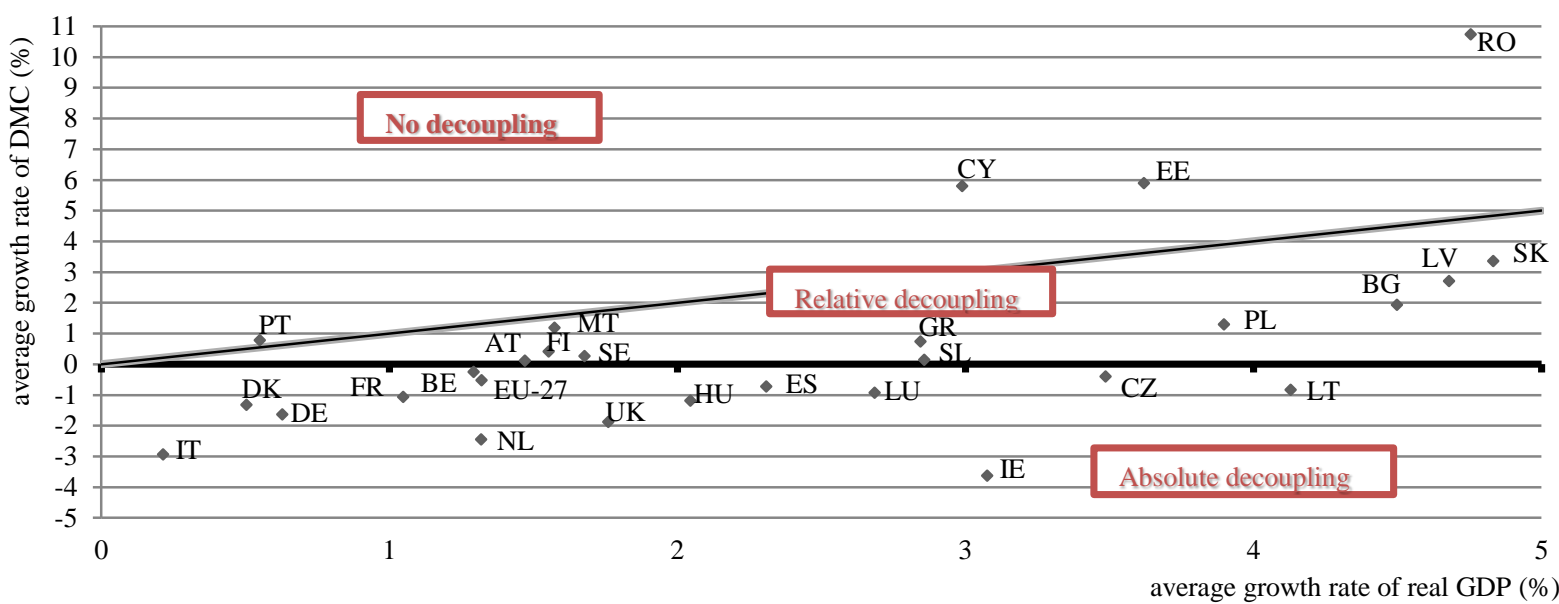

Figure 3 Domestic material consumption and GDP average growth rates by EU countries, 2000-2009 Source: Eurostat (2013a), own elaboration

economic growth, that is, a positive average growth rate of the GDP associated with a negative average growth rate of the DMC, was typical of thirteen countries (see Figure 3, below the black line, which is also the horizontal axis). However, in this period, the impacts of the economic crisis showed themselves, especially in 2008 and 2009, and they resulted in a decline of the DMC. This also results from the analysis of resource productivity (see above). In the period 20002007, absolute decoupling (decreasing DMC) only took place in six countries, specifically Italy, Germany, Malta, the Netherlands, Hungary and the UK. Thus, due to the negative impacts of the crisis, seven additional countries showed absolute decoupling in 2000-2009. As mentioned above, Ireland achieved a significant decrease in DMC due to the crisis $(-36.1 \%$ in 2008 and $-19.654 \%$ in 2009 ). This resulted in absolute decoupling in the period 2000-2009 (see Figure 3 ). Of the remaining EU member states, ten showed relative decoupling, with the DMC on average increasing at a slower rate than the GDP in the period 2000-2009 (the area bounded by the horizontal axis and the $45^{\circ}$ line in Figure 3 ). No decoupling was achieved in the four remaining countries, Portugal, Cyprus, Estonia and Romania (above the $45^{\circ}$ line in Figure 3). Their DMC was on average growing faster than their GDP, indicating that the resource productivity declined in those countries in the period 20002009.

We can see that the whole EU-27 showed absolute decoupling in the period 2000-2009 but the development was affected by the impacts of the economic 
crisis; moreover, the trends were different in individual countries. In the period 2000-2007, the whole EU27 only achieved relative decoupling. There were also more countries with no decoupling in the period 2000-2007; besides the four countries mentioned above with no decoupling in the period 2000-2009, Denmark, Spain, Lithuania and Slovenia showed higher growth rates of their DMC than their GDP. The absolute decoupling in Denmark, Spain, Latvia and Ireland and the relative decoupling in Lithuania or Slovenia in a longer average period, which also includes two years of crisis $(2008,2009)$, can be understood as evidence of the fact that greater resource productivity is more achievable in times of economic slowdown or recession.

It is possible to complete the previous analysis with a simple regression analysis to point out the relation between GDP and DMC in the EU countries. Using cross-country regression and the least squares method, the directly proportional relationship between the average growth rates of these two variables in the period 2000-2009 results from equation (1):

$$
\begin{gathered}
\Delta D M C=--0,018+0.743 \times \Delta G D P+\mu_{i}, \quad(1) \\
N=23 ; R^{2}=0.454 ; \text { adj } R^{2}=0.428 ; D W=2.260 .
\end{gathered}
$$

In equation (1), the average growth rates (or rates of change) of the DMC and GDP variables in 2000 2009 are expressed with the symbol " $\Delta$ ". Four countries were excluded from the analysis - Estonia, Ireland, Cyprus and Romania - because of high residuals, so these represent outliers. Including these countries in the analysis would lead to a violation of the model assumptions regarding the homoskedasticity of the errors and the normality of the error distribution according to the Jarque-Bera (J-B) test. In some cases, by excluding only some of these countries, the assumption of no serial correlation of the errors would also be violated. Countries such as Romania, Estonia and Cyprus showed high average growth rates of both variables and no decoupling; on the contrary, especially the economy of Ireland showed absolute decoupling, that is, a relatively high growth rate of the GDP with a negative growth rate of the DMC in the period 2000-2009 (see Figure 3). The econometric verification showed no problems with meeting the assumptions of the model when the sample of 23 EU countries, the EU-27 after excluding these outliers, was used. This means the absence of autocorrelation and heteroskedasticity and the existence of normal distribution of the residuals.

The coefficient of determination (the goodness of fit of this model) in equation (1) is $45.364 \%$. Therefore, besides the GDP, there can be other important variables that significantly affect the rate of DMC change. The correlation coefficient between these two variables in the $27 \mathrm{EU}$ countries is $0.584(58.449 \%)$ but it is higher after the exclusion of the 4 outliers: for the 23 countries included in the above regression, it is $0.674(67.353 \%)$. Including all the $27 \mathrm{EU}$ countries in the analysis would increase the slope of the function from 0.743 to 1.252 . However, this would lead to the violation of the assumptions of the model (see above).

Overall, this regression analysis can be regarded as a supplementary tool that partly confirms the trends that have already been detected in the previous analysis of resource productivity and DMC in the EU and its countries. To sum up, a stable or decreasing DMC is often associated with relatively low GDP growth rates, whereas high GDP growth rates tend to be associated with moderate or high increases in the DMC. However, this relationship is not so straightforward, which is also confirmed by the fact that there are more outliers among the EU countries that cannot be included in the regression and more countries are not adjacent to the $45^{\circ}$ line. This can be seen in Figure 3, in which more of the EU countries show relative or even absolute decoupling even those with higher GDP growth rates. Thus, the above-mentioned aspect is more evident from the time point of view. It means that in good times both variables grow at higher rates and in bad times they both grow slower or decrease.

\subsection{Development of Energy Consumption of Transport}

The second monitored headline indicator, referred to as energy consumption of transport (TEC) relative to GDP, compares the growth of the transport energy consumption with the growth of the GDP. Figures 4 and 5 present the results from using the index reflecting the development in time.

Figure 4 indicates that until 2009 the energy consumption of transport relative to GDP in the EU was decreasing, with the exception of the years 2003 and 2004. In 2003 and 2004, the energy consumption of transport in percentage terms increased slightly more than the GDP (in 2003, the TEC increased by $1.465 \%$ and the GDP by $1.451 \%$; in 2004 the TEC increased by $2.985 \%$ and the GDP by $2.532 \%$ ). Therefore, except in these two years, relative decoupling took place in the EU until 2007. Overall, in 1990-2007, the annual energy consumption of transport was mostly growing. This trend was broken by the economic crisis and the corresponding slowdown and downturn in economic activity when the consumption of transport decreased by $-0.647 \%,-2.74 \%$ and $-0.422 \%$ in 2008 , 2009 and 2010, respectively. The correspondent GDP growth rates were $0.341 \%,-4.294 \%$ and $2.091 \%$ in 2008, 2009 and 2010, respectively. This resulted in an increase in energy consumption of transport relative to GDP in 2009, because the GDP decreased more than the energy consumption of transport $(-4.294$ and $2.74 \%$, respectively). In contrast, in 2008 and 2010, 


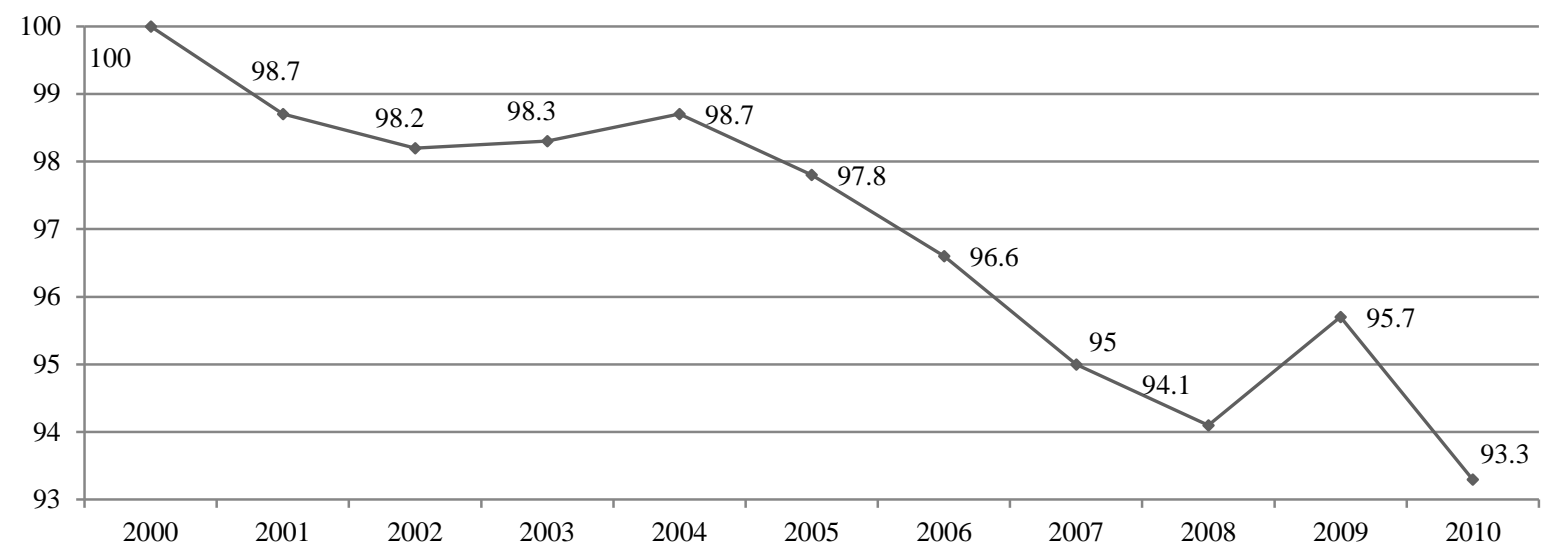

Figure 4 Energy consumption of transport relative to GDP in the EU-27, index $(2000=100)$ Source: Eurostat (2013a), own elaboration

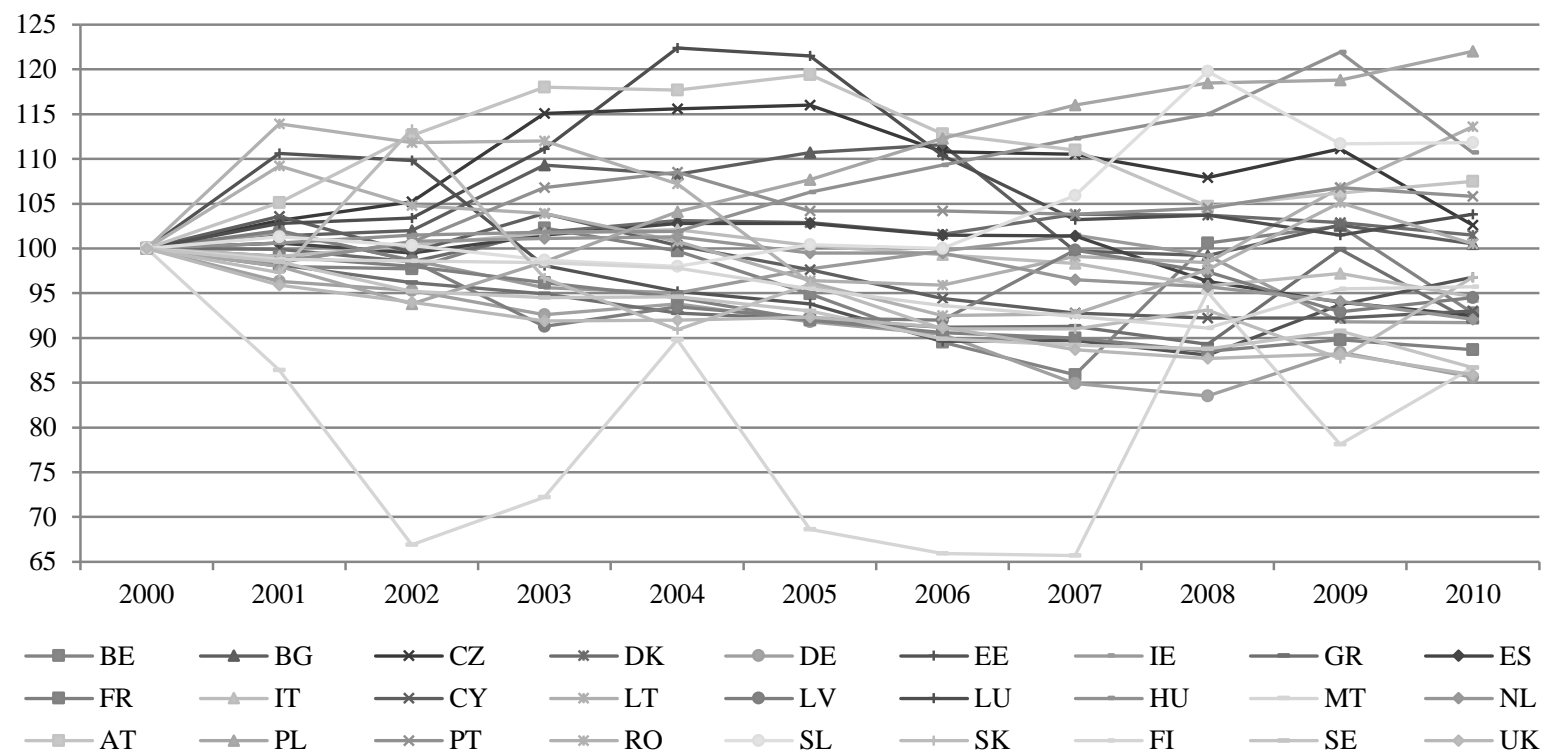

Figure 5 Energy consumption of transport relative to GDP in the EU countries, index $(2000=100)$

Source: Eurostat (2013a), own elaboration

absolute decoupling took place because of the negative growth rates of consumption associated with the positive GDP growth rates. This resulted in a decrease in energy consumption of transport relative to GDP in these years.

Overall, it can be seen that the development of the TEC relative to the GDP often resembles that of resource productivity but in the opposite direction. This is because of the fact that in the composition of the resource productivity indicator the GDP is in the numerator, whereas in the energy consumption of transport relative to GDP it is in the denominator. Thus, the annual growth rate of resource productivity in the overall EU economy was positive in the period 2000-2003, whereas that of the TEC relative to the GDP was negative in 2000-2002. In 2004, and regarding the TEC relative to the GDP in 2003 as well, after the period of economic slowdown, the resource productivity decreased annually and the TEC relative to the GDP increased slightly. Then the trend of the previous development (before 2004) continued until 2008. This means a positive growth rate of resource productivity and a negative growth rate of the TEC relative to the GDP. In 2009, due to the crisis, the resource productivity increased even more, but the TEC relative to the GDP increased too because of the smaller percentage decrease in the energy consumption of transport than in the GDP.

The development of the TEC relative to the GDP in the EU countries is depicted in Figure 5. As for resource productivity, we can see that the development of this headline indicator in Malta has significantly deviated from that in other countries again. This country shows significant increases as well as signifi- 
cant decreases in the TEC relative to the GDP in particular years. This means that the development of this indicator in the EU has been variable. Overall, the largest increase in the energy consumption of transport relative to GDP in the period 2000-2010 was apparent in Poland (22\%), followed by Latvia, Slovenia, Hungary, Austria and Portugal. In all these countries, the increase was greater than 5\%. Increases lower than 5\% were typical of Luxembourg, the Czech Republic, Denmark, Romania and Bulgaria. In the remaining sixteen EU countries, this indicator decreased, whereas the largest decrease was shown by Germany, the UK, Malta, Sweden and France (by more than 10\%). In the whole EU, the indicator decreased by $-6.7 \%$ (see also Figure 4). Looking at the period 2000-2009, the increase in the indicator was most significant in Hungary $(21.9 \%)$ because of the large increase in 2009 , whereas it subsequently decreased in 2010 . On the contrary, in the period 2000-2009, the largest decrease in the indicator was shown by Malta ($21.9 \%$ ) because of the large decrease in the indicator in 2009. Thus, the trends in the EU countries varied but no other country achieved a change greater than $20 \%$ in the period 2000-2009.

As stated above, in 2009, the decrease in the GDP exceeded the decrease in the TEC in the EU. The same was true of most of the EU countries. Therefore, in terms of this indicator, the economic crisis positively affected decoupling, especially in 2008 and 2010, when the growth rates of the GDP were positive whereas those of the TEC were negative. The most obvious exception in these terms is the abovementioned economy of Malta with the highest decrease in the TEC, also relative to the GDP, in 2009. In contrast, the DMC increased in this country by $62.319 \%$ in 2009 , which was the only increase in this indicator in this year among the EU countries.

In order to provide a better indication of the decoupling in individual countries and the $\mathrm{EU}$ as a whole, the growth rates of the TEC were compared with those of the real GDP analogous to the previous analysis of DMC and GDP. For the TEC indicator, the data were available for the period 2000-2010. Thus, longer time series were used in comparison with the previous analysis of decoupling. Overall, the development of the energy consumption of transport relative to the GDP seems to be less favourable than the development of the total domestic material consumption in the EU countries (see Figure 6). Absolute decoupling was only typical of three countries, France, Germany and Italy, in which the GDP was on average growing annually and the TEC was declining in the period 2000-2010 (see Figure 6, below the black line, which is also the horizontal axis). This is also true of the period 2000-2009; moreover, Malta showed absolute decoupling in this period. This is the result of a significant decrease in the energy consumption of transport relative to the GDP in 2009 (see Figure 5).

However, the average rate of the TEC decline in 2000-2010 was very slight, especially in France and Italy $(-0.094$ and $-0.181 \%$, respectively). It was slightly higher in Germany $(-0.631 \%)$. The relative decoupling in 2000-2010 was typical of thirteen countries (the area bounded by the horizontal axis and the $45^{\circ}$ line in Figure 6). The same is also true of the period 2000-2009 with the exception of Malta (see above) and Belgium, where no decoupling occurred in 2000 2009. In 2010, the GDP increased in Belgium and the TEC decreased further. Consequently, the energy consumption of transport relative to the GDP decreased too, which subsequently changed the average trends in decoupling. Eleven remaining countries showed no decoupling in 2000-2010, specifically Denmark, Portugal, Austria, Hungary, Luxembourg, Slovenia, the Czech Republic, Latvia, Poland, Bulgaria and Romania. Whereas in the older member states, especially in Denmark, Portugal and Austria, no decoupling was predominantly connected with lower rates of both, in the new member states, it was predominantly connected with higher rates of both.

Finally, the analysis of decoupling between the TEC and the GDP average growth rates can be completed with a similar model to that used to examine the relation between the DMC and the GDP average growth rate. Thus, simple cross-country regression and the least squares method were also used in this case, but in the period 2000-2010 because the longer time series were available. However, in this case, the econometric verification showed no problems with meeting the assumptions of the model for the residuals when the sample of $27 \mathrm{EU}$ countries was used. This means the absence of autocorrelation and heteroskedasticity and the existence of normal distribution of the residuals. The last one was verified by the J-B test again. The model is expressed by equation (2):

$$
\triangle T E C=-0.008+1.247 \times \triangle G D P+\mu_{i},
$$
$N=27 ; R^{2}=0.739 ; \operatorname{adj} R^{2}=0.729 ; D W=1.704$.

In equation (2), the average growth rates (or rate of change) of the TEC and GDP variables in 2000-2009 are expressed with the symbol " $\Delta$ ". The correlation coefficient between these two variables in the $27 \mathrm{EU}$ countries is $0.86(85.987 \%)$ and the coefficient of determination is 0.739 (73.937\%). This indicates higher figures than in the case of the previous model expressing the relationship between the DMC and the GDP growth rates. The slope of the line expressed by formula (2) is higher than that expressed by (1) as well. It would be higher (i.e. 1.252) in the first model (1) assuming that all $27 \mathrm{EU}$ countries are included; however, these assumptions in previous model were not met. It is true that different time periods were used 


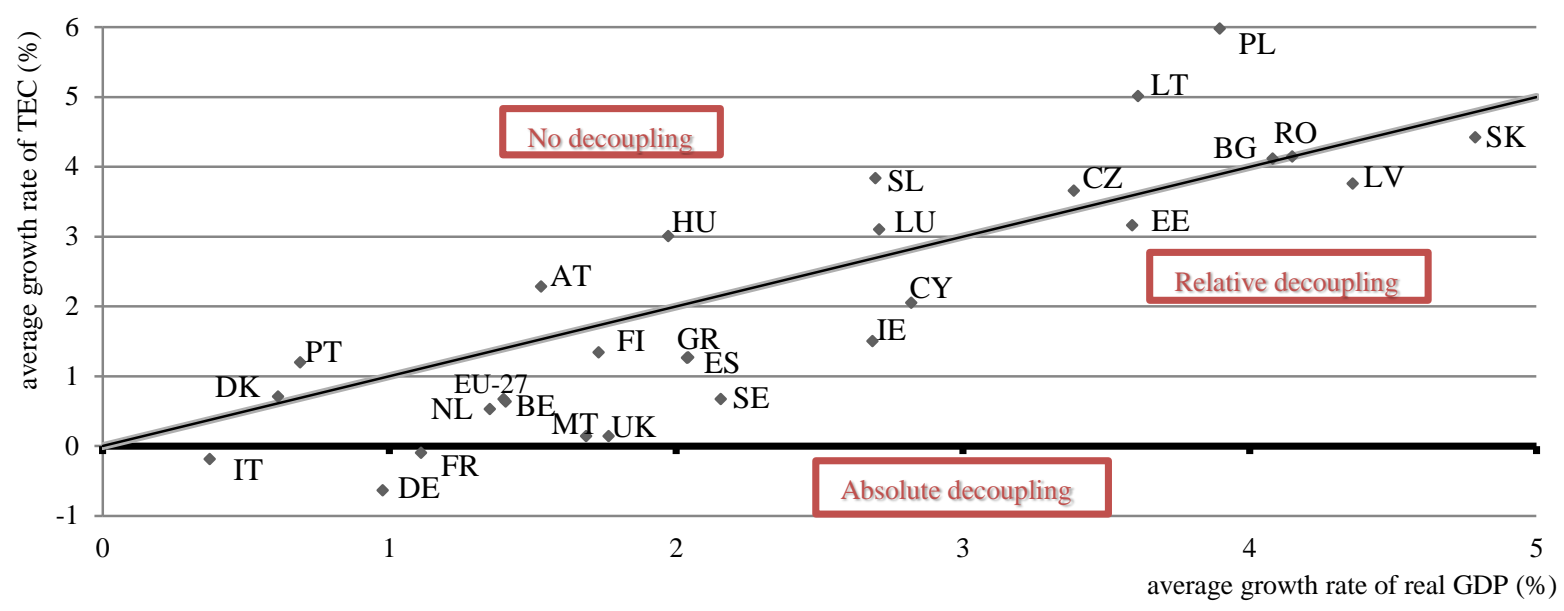

Figure 6 TEC and GDP average growth rates by EU countries, 2000-2010

Source: Eurostat (2013a), own elaboration

in the calculation of the average growth rates of the variables. If the period 2000-2009 is used to determine the relation between the TEC and the GDP growth rate, the slope will slightly decline from 1.247 to 1.132 . In addition, the correlation coefficient will decrease from 0.86 to 0.811 and the coefficient of determination from 0.739 to 0.658 . Despite the fact that the coefficients and slope decreased, they are still higher than in the previous model (equation (1)). Whether the period $2000-2010$ or the period 20002009 is used, these models and their coefficients are statistically significant and no problems were detected in terms of meeting the assumptions for the residuals.

To sum up, it can be confirmed again that a positive relationship exists between the growth rate of energy consumption of transport and the growth rate of GDP in the EU. In this case, the positive correlation is higher than in the previous case. The positive relationship is more straightforward than the relationship between the DMC and the GDP growth rate even at the cross-country level. It means that no country with a relatively high GDP growth rate showed absolute decoupling and overall only three countries with relatively low growth rates achieved this kind of decoupling.

\subsection{Development of Greenhouse Gas Emissions}

Tackling the problem of climate change is necessary in order to approach a sustainable development path. Therefore, two additional indicators included in the Climate Change and Energy theme were examined. One of them is also the indicator of the Sustainable Transport theme.

\subsubsection{Development of Greenhouse Gas Emis- sions in the Overall Economies}

Firstly, the development of total greenhouse gas emissions (GHGs) indexed to 1990 is examined (see Fig- ure 7). The year 1990 is the Kyoto base year for the non-fluorinated gases for most Annex I Parties of the Kyoto Protocol. We can see that the development has varied significantly among the EU member states. In the whole EU-27, the GHGs decreased by $9 \%$ until 2000 and by $15 \%$ until 2010 in comparison with the base year 1990. Thus, the whole EU met the target of the Kyoto Protocol to reduce the emissions by $8 \%$ in $2010 .{ }^{4}$ However, this was only feasible on the assumption that flexible reduction in the EU countries was possible. This means that some countries have had to reduce their emissions to a larger extent.

In the period 1990-2010, the GHGs decreased most significantly in Lithuania $(-58 \%)$, Latvia ($55 \%)$, Romania $(-52 \%)$, Estonia $(-50 \%)$, Bulgaria, Slovakia, Hungary (by $-30 \%$ and more) and the Czech Republic $(-29 \%)$. They were followed by Germany and the UK $(-25 \%$ and $-23 \%$, respectively). Eight other countries reduced their emissions to a lesser extent. An increase was typical of nine remaining countries, with the highest one in Cyprus (68\%), followed by Malta (49\%), Spain (26\%), Portugal (18\%), Greece $(13 \%)$, Ireland $(11 \%)$, Austria $(8 \%)$ and Finland and Slovenia (both by 6\%) (see Figure 7).

Until 2000, the GHGs also increased in France, Belgium, Netherlands and Italy in comparison with the base year 1990. Regarding the emissions' reduction, the downward trend was most significant in the period 1990-2000 in the Baltic economies, whereas in the period 2000-2010, the emissions increased slightly

\footnotetext{
4 This target had already been met in several years of the 1990s. However, some temporary emission increases resulted in this target being missed. Since 2000, this target has continually been met every year with the exception of 2003 and 2004.
} 


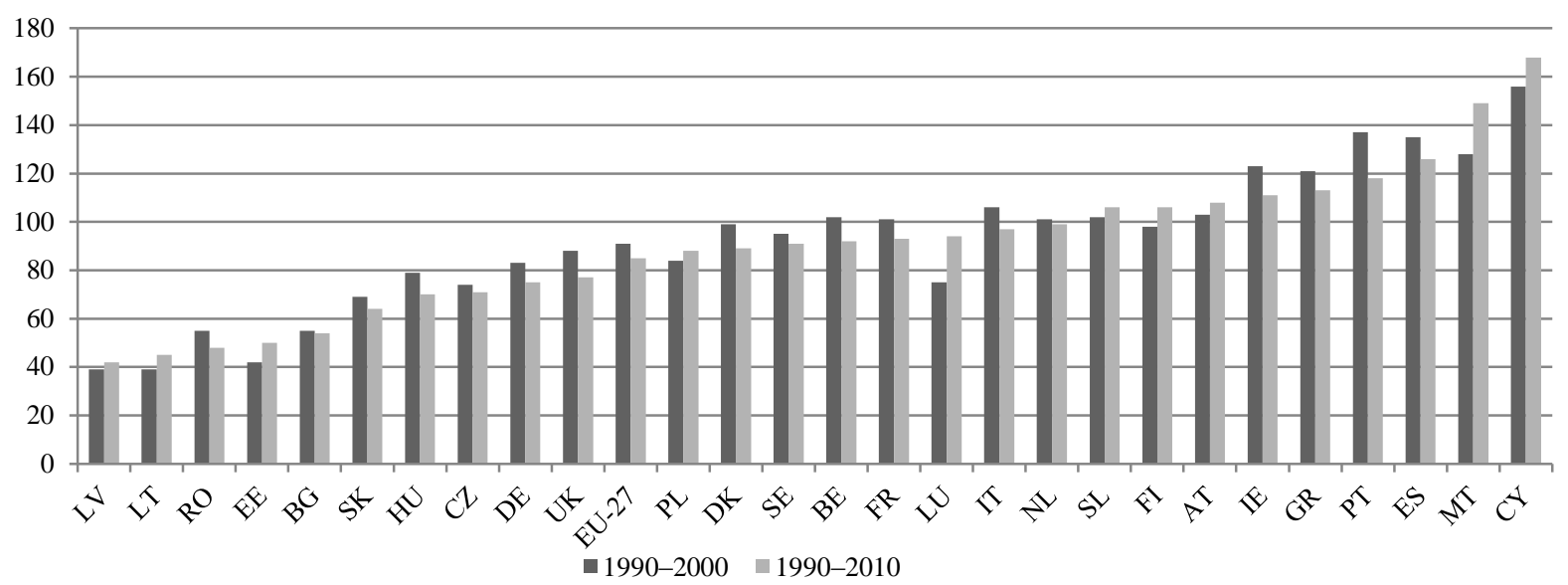

Figure 7 Total greenhouse gas emissions (in $\mathrm{CO}_{2}$ equivalents) indexed to 1990, index $(1990=100)$

Source: Eurostat (2013a), own elaboration

in all three countries. This is likely to be associated with the high growth rates of the GDP in these economies in the period 2000-2007. Due to the crisis in 2008, the GHG emissions dropped annually in most of the EU countries, with the exception of Slovenia, Slovakia, Belgium and Germany, whereas in the last one the annual emissions did not change. In 2009, they dropped in all the EU countries. Due to the recovery in the majority of the EU economies, the emissions increased again in most of them in 2010, with the exception of Greece, Portugal, Spain, Cyprus, Ireland and Romania. These are mainly the countries with the most significant negative impacts of the economic crisis.

\subsubsection{Greenhouse Gas Emissions from Tran- sport}

Regarding the greenhouse gas emissions from transport, the situation in the EU and its countries has been quite different in comparison with the total GHGs in the EU economies (see Figure 8). In the whole EU, the GHG emissions from transport were by $20.039 \%$ higher in 2010 than in 1990, whereas in the period $1990-2000$ they increased by $17.687 \%$ and in the period $2000-2010$ by $1.999 \%$. This was again the result of the economic crisis in the more recent partial period when the emissions in this sector decreased annually in 2008, 2009 and 2010 (by $-1.871 \%$, $2.742 \%$ and $-0.506 \%$, respectively). Regarding the development in the individual countries, only six new member states reduced their GHG emissions in the period 1990-2000, specifically Lithuania $(-55.849 \%)$, Estonia, Latvia (by more than $-20 \%$ ), Bulgaria, Slovakia and Romania (by more than $-10 \%$ ). Thus, the most significant reduction was achieved by Baltic economies. Conversely, the highest increase in emissions, i.e. higher than $50 \%$, was shown by the economies of Ireland, Portugal, Luxembourg, the Czech
Republic and Spain. In the subsequent ten-year period of 2000-2010, the situation changed and the emissions were only reduced in the economies of Germany, France, the UK, Italy, Portugal and Belgium, and only in Germany was this reduction higher than $10 \%$. Conversely, all the new member states experienced significant increases in GHG emissions from transport in this period, which are among other issues related to the high growth rates in most of these countries.

However, the development of emissions in this sector has also been affected by the economic crisis. In 2008, the GHG emissions declined in many of the EU countries, with the exception of ten countries, particularly new member states such as Slovenia and Romania, but also three Benelux countries. In 2009, which is the year of the most significant impacts of the crisis, an increase in emissions took place in only four countries, Greece, Malta, Poland and Cyprus. Later, in 2010, in terms of recovery, the emissions increased in fourteen EU countries again. The most significant decrease in GHG emissions in 2010 was achieved by the economy of Greece (10.996\%), which was one of the economies affected the most by the crisis.

In the whole period 1990-2010, the GHG emissions from transport decreased only in Lithuania, Estonia and Germany. Conversely, the increase was most significant in Luxembourg (137.821\%), Ireland (126.768\%), the Czech Republic (124.643\%), Poland (122.9\%), Cyprus (96.851\%), Slovenia (91.779\%) and Portugal (83.684\%). In the Czech Republic and Poland, this trend is in contradiction to the development of emissions in the economy as a whole, for which the emissions dropped by $29 \%$ and $12 \%$, respectively, in this period. From the above-mentioned countries with the highest levels of emissions from transport, the overall emissions also decreased in Luxembourg but less significantly $(-6 \%)$. In contrast, the economies of 


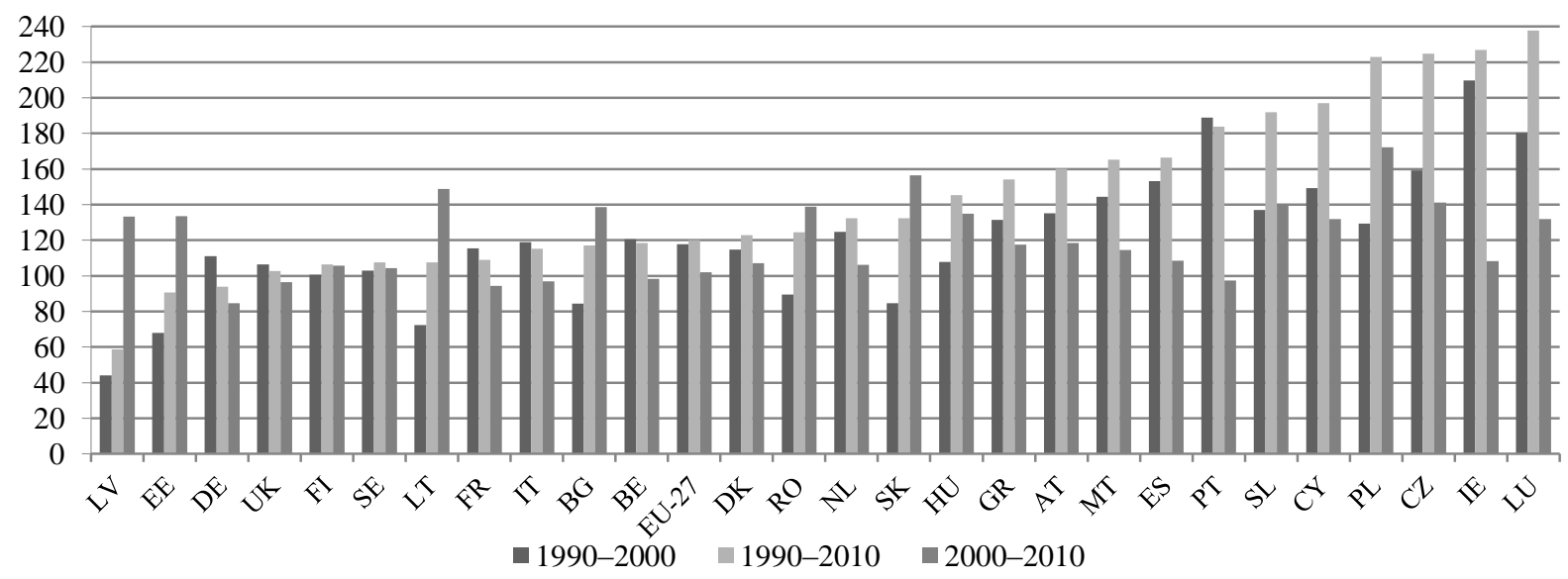

Figure 8 Greenhouse gas emissions from transport (in $\mathrm{CO}_{2}$ equivalents) indexed to 1990, index $(1990=100)$ Source: Eurostat (2013a), own elaboration

Cyprus and Malta not only dominated in GHG emissions growth in the economy as a whole but also showed significant increases in these emissions from the transport sector.

Overall, we can see that the development of GHG emissions, whether in transport or in the economy as a whole, has varied substantially across the EU countries. In general, the transport sector seems to be problematic with regard to the reduction of GHG emissions in the EU as well as in most of its countries. Even though the total emissions have been decreasing in the EU and in the majority of its countries, the opposite has been true concerning the emissions from transport in the whole EU as well as in most of its countries.

\subsection{Rationale of Development and Summary of the Facts}

Industrialized countries show differences in the energy intensity of the GDP, in the structure of the energy resources and energy consumption in sectors such as industry, transport, etc., and in the standards and styles of living. The energy sources that do not produce GHGs, such as atomic, wind energy or water power, are also used to varying degrees. All these and many other factors affect the domestic material consumption, resource productivity and GHG emissions in individual sectors as well as in overall economies. The possibilities to reduce the emissions and to increase the resource productivity, among others, depend on the initial position of the economy. The former transition countries of Central and Eastern Europe, having undergone economic transformation, have had much greater possibilities to reduce their GHG emissions and energy and material consumption as well as to increase their resource productivity due to previous inefficient use of resources. Similarly, Germany had such possibilities. This was associated with the reunification and modernisation of the former East Germany.

Overall, the German economy has been one of the most successful economies as regards GHG emission reductions, and its resource productivity also increased from 2000 to 2009. The domestic material consumption decreased by $-13.785 \%$ in the period 2000-2009. This led to an increase of $22.667 \%$ in resource productivity in the same period. Even though two years of significant impacts of the economic crisis are included in this period, specifically 2008 and 2009, which led to better results, the resource productivity also significantly increased in the period 2000-2007 (by $21.333 \%$ ). This corresponds to the decrease of $8.681 \%$ in the DMC in this period. GHG emissions in the German economy had been decreasing since 1990 and until 2010 they decreased by $25 \%$. In the transport sector, the emissions decreased by $-6.063 \%$ in the period $1990-2010$ and even by $15.466 \%$ in the more recent period 2000-2010, which was the highest drop in emissions among the EU countries in this period. The positive results of this economy as regards GHG emission reduction have also had positive impacts on meeting the commitments resulting from the Kyoto Protocol, even though in some countries, such as Cyprus, Malta, Spain, Portugal, Greece and Ireland, these emissions have significantly increased.

Most of the new member states, with the exception of Cyprus, Malta and Slovenia, have shown significant decreases in GHG emissions since 1990. The reasons especially lie in the process of transformation that has taken place in these economies. Conversely, the above-mentioned new member states with the highest increase in emissions are also the economies achieving the highest GDP per capita among the new member states. However, in spite of greater possibilities for emission reduction in the new member states, the 
transport sector has shown rather unfavourable trends, similarly to the majority of the older member states. Overall, in the period 1990-2010, the GHG emissions from the transport sector decreased only in Lithuania, Estonia and Germany.

The material and energy consumption, the resource productivity as well as the development of the GHG emissions also depend on development of the economic activity, i.e. the GDP. The periods of economic crisis were accompanied by an economic downturn, which also led to the corresponding development of the examined indicators, that is, a decrease in the GHG emissions or a slowdown in their growth rates. Especially in 2009, these emissions decreased in all the EU countries. Similarly, a stable or decreasing DMC has often been associated with relatively low GDP growth rates, whereas high GDP growth rates tend to be associated with moderate or high increases in the DMC. On the whole, the changes in trends over 2008 and 2009 did not result from intense structural changes but rather from a temporary interruption of longer-term trends, which also confirmed the conclusions of Eurostat and the European Commission (2011).

\section{Conclusion}

In this paper, achieving sustainable development path in the EU was examined using selected Sustainable Development Indicators of Eurostat. Specifically, resource productivity, domestic material consumption, energy consumption of transport and greenhouse gas emissions in the EU and its economies, particularly in their transport sectors, were examined.

A stable or decreasing DMC in the EU has often been associated with relatively low GDP growth rates, whereas high GDP growth rates tend to be associated with moderate or high increases in the DMC. Even more significantly, this is also true of the relation between the development of the GDP and that of the TEC. The development of the DMC is reflected in the resource productivity, which is generally higher in times of economic slowdown or downturn. Overall, the energy consumption of transport has shown less favourable development in comparison with the total domestic material consumption in the EU and its countries. This can also be confirmed by the existence of absolute decoupling in the whole EU in the period 2000-2009. More generally, a larger number of the EU countries have shown decoupling between the GDP and the DMC in comparison with that between the GDP and the TEC. Therefore, it can be said that when the period of economic crisis is included in the calculation, more EU countries are able to achieve decoupling for the above-mentioned reasons. The regression analysis showed that in the EU a more sig- nificant positive relationship exists between the average growth rates of the GDP and the TEC than between the GDP and the DMC average growth rates. This is more straightforward even at the cross-country level.

The last analysed area of sustainable development was related to greenhouse gas emissions. The development of GHG emissions, whether it is in the transport sector or in the economy as a whole, has also varied substantially across the EU countries. The transport sector seems to be problematic not only due to its growing energy consumption, but also due to its insufficient reduction of GHG emissions. However, it is obvious that the first area has also encouraged the second one. Even though the total emissions have been decreasing in the EU and the majority of its countries, for the emissions from transport, the opposite has been true. In the transport sector, the emissions decreased in the period 1990-2010 only in Lithuania, Estonia and Germany, whereas in the overall economy, they only increased in Cyprus, Malta, Ireland, Austria, Finland, Slovenia and three Southern economies, Spain, Portugal, Greece. Consequently, most of the new member states have reduced the GHG emissions from their overall economies within the transformation process that has taken place in their economies. They have not been so successful in reducing these emissions from the transport sector.

Differences exist between the individual EU economies as regards the energy intensity of GDP, structure of energy sources or energy consumption in individual sectors and overall economies. These have resulted in differences in the development of the examined indicators. Some countries have shown specific characteristics; for example, the economy of Malta has shown highly variable development of the energy consumption of transport relative to the GDP. Overall, one of the most successful countries in the EU seems to be Germany with regard to the development of all the indicators examined in this paper.

However, the EU has still not been on a sustainable development path as regards the trends of development in the examined indicators. The reasons are, among others, the permanent negative trends in several countries, the overall unfavourable trends in the transport sector as well as the fact that most of the improvements have taken place in times of economic slowdown or downturn. The latter indicates that such improvements have not been the result of the structural changes that are necessary to achieve decoupling and to approach the sustainable development path. Even if the reduction of GHG emissions has been successful in the EU and most of its countries in order to meet the target of the Kyoto Protocol, much work 
still needs to be carried out in other areas of sustainable development.

A large number of Sustainable Development Indicators have been developed and monitored in the EU in order to examine the EU's sustainable development path. These indicators overlap. Therefore, in this paper, only some of them were chosen as representatives to examine how the EU has approached the sustainable development path, whereas others were omitted. Therefore, a further challenge should be to find methods to examine the sustainable development path in a complex and comprehensive way that also shows all the necessary aspects of sustainable development.

\section{References}

ADELLE, C., PALLEMAERTS, M. (2009), Sustainable development indicators. An Overview of Relevant Framework Programme Funded Research and Identification of Further needs in view of EU and International Activities. European Commission, European Research Area.

COMMISSION OF THE EUROPEAN COMMUNITIES (2005). Sustainable Development Indicators to monitor the implementation of the EU Sustainable Development Strategy. Brussels, 9.2.2005. SEC(2005) 161 final.

DALY, H.E. (1996). Beyond Growth. Boston: Beacon Press.

EUROPEAN COUNCIL (1999). Presidency Conclusions, Helsinki European Council, 10-11 December 1999.

EUROPEAN COUNCIL (2001). Presidency Conclusions - Göteborg European Council. SN 200/1/01 Rev 1, 15 - 16 June 2001.

EUROSTAT AND EUROPEAN COMMISSION (2011). Sustainable Development in the European Union. 2011 Monitoring Report of the EU Sustainable Development Strategy. Luxembourg: Publications Office of the European Union.

OECD (2001). Sustainable Development: The Critical Issues. Paris: OECD.

OECD (2002). Sustainable Development. Indicators to measure Decoupling of Environmental Pressure from Economic Growth. SG/SD(2002)1/FINAL.

OECD (2003). OECD Environmental Indicators. Development, Measurement and Use. Reference Paper.

WCED (1987). Report of the World Commission on Environment and Development: Our Common Future. $\mathrm{UN}$-documents.

\section{Additional resources}

COMMISSION OF THE EUROPEAN COMMUNITIES (2002). Communication from the
Commission to the European Parliament, the Council, the Economic and Social Committee and the Committee of the Regions: Towards a global partnership for sustainable development. Brussels, 13. 02. 2002. $\operatorname{COM}(2002) 82$ final.

COMMISSION OF THE EUROPEAN COMMUNITIES (2001). Communication from the Commission: A Sustainable Europe for a Better World: A European Union Strategy for Sustainable Development. Brussels, 15. 5. 2001. COM(2001)264 final.

EUROPA (2009). Summaries of EU legislation. Environment. Sustainable development [On-line]. Last updated: 18. 12. 2009. Available at: <http://europa.eu/ legislation_summaries/environment/sustainable_deve lopment/128117_en.htm>.

EUROPEAN COMMISSION (2014). Environment. Sustainable Development [on line]. Last updated: 03.06.2014. Available at: <http://ec.europa.eu/envi ronment/eussd/>.

EUROSTAT (2013a). Statistics. Sustainable development indicators. Indicators [On-line]. Last update 12. 07. 2013. Available at: <http://epp.eurostat.ec.europa. eu/portal/page/portal/sdi/indicators $>$.

EUROSTAT (2013b). Statistics. Sustainable development indicators. Indicators for monitoring the EU Sustainable Development Strategy. Context. [On-line]. Last update 12. 07. 2013. Available at: $<$ http://epp.eurostat.ec.europa.eu/portal/page/portal/sdi /context>.

EUROSTAT (2014a). Statistics. Sustainable development indicators [On-line]. Last update 05. 06. 2014. Available at: <http://epp.eurostat.ec.europa.eu/portal/ page/portal/sdi/indicators $>$.

EUROSTAT (2014b). Sustainable development indicators. Climate Change and Energy. [On-line]. Last update 25. 06. 2014. Available at: <http://epp.eurostat. ec.europa.eu/portal/page/portal/sdi/indicators/theme6>.

EUROSTAT $(2014 \mathrm{c})$. Sustainable development indicators. Sustainable consumption and production. [Online]. Last update 13. 05. 2014. Available at: $<$ http://epp.eurostat.ec.europa.eu/portal/page/portal/sdi /indicators/theme2>.

EUROSTAT (2014d). Sustainable development indicators. Sustainable transport. [On-line]. Last update 25. 06. 2014. Available at: <http://epp.eurostat.ec. europa.eu/portal/page/portal/sdi/indicators/theme7>.

FEEM (2011). Sustainability Index. Methodological Report. [On-line]. Available at: <http://www.feemsi. org/documents/methodological_report2011.pdf >. 
HEDIGER, W. (2004). Weak and Strong Sustainability, Environmental Conservation and Economic Growth. Agricultural and Food Economics. Swiss Federal Institute of Technology Zurich, ETH Zentrum
(SOL), CH-8092 Zurich. Available at: <http://www.cer.ethz.ch/sured_2004/programme/sure d_hediger.pdf $>$. 